\title{
Effects of PEEP on the thermoregulatory responses during TIVA in patients undergoing tympanoplasty
}

\author{
Tae-Hun An, and Jung-Woo Yang \\ Department of Anesthesiology and Pain Medicine, School of Medicine, Chosun University, Gwangju, Korea
}

Background: During general anesthesia, core temperature decreases, largely due to heat loss caused by peripheral vasodilation, resulting in heat redistribution to peripheral tissues. Multiple factors contribute to body temperature regulation during general anesthesia. It was reported that baroreceptor unloading by positive end-expiratory pressure (PEEP) attenuates anesthetically-induced hypothermia. So, we evaluated the effects of PEEP on thermoregulatory responses during total intravenous anesthesia (TIVA).

Methods: Forty healthy patients scheduled for tympanoplasty were allocated two groups, Group ZEEP (zero end-expiratory pressure, $\mathrm{n}=20$ ) and Group PEEP (PEEP application of $5 \mathrm{cmH}_{2} \mathrm{O}, \mathrm{n}=20$ ). Ambient temperature was maintained at $22-24^{\circ} \mathrm{C}$, and anesthesia was induced and maintained with propofol-remifentanil. The core temperature and the temperature difference between forearm and fingertip skin were monitored before and after the induction of general anesthesia having a duration of 180 minutes.

Results: The core temperature gradient (Ti-Tf) was higher in patients with ZEEP than with PEEP. The core temperature was maintained at a higher level in patients with PEEP. Additionally, the vasoconstriction threshold was higher in patients with PEEP.

Conclusions: It seems that PEEP attenuates anesthetically-induced hypothermia during TIVA. (Korean J Anesthesiol 2011; 61: 302-307)

Key Words: Positive end-expiratory pressure (PEEP), Thermoregulation, Total intravenous anesthesia (TIVA), Vasoconstriction threshold.

Received: March 3, 2011. Revised: 1st, April 13, 2011; 2nd, April 19, 2011; 3rd, April 20, 2011. Accepted: April 21, 2011.

Corresponding author: Tae-Hun An, M.D., Department of Anesthesiology and Pain Medicine, School of Medicine, Chosun University, 588, Seoseok-dong, Dong-gu, Gwangju 501-717, Korea. Tel: 82-62-220-3223, Fax: 82-62-223-2333, E-mail: than@chosun.ac.kr

(c) This is an open-access article distributed under the terms of the Creative Commons Attribution Non-Commercial License (http:// creativecommons.org/licenses/by-nc/3.0/), which permits unrestricted non-commercial use, distribution, and reproduction in any medium, provided the original work is properly cited. 


\section{Introduction}

During general anesthesia, body heat is redistributed from the body core to the peripheral regions mainly by peripheral vasodilation and arteriovenous shunt expansion. Body temperature redistribution accounts for the core temperature decrease $[1,2]$. When the core temperature reaches the vasoconstriction threshold during this process, arteriovenous vasoconstriction occurs, and heat loss is reduced. Core temperature redistribution is minimized, and the body temperature decrease is repressed, leading to an equilibrium state. The body temperature is strictly regulated within a $0.2^{\circ} \mathrm{C}$ temperature range by vasoconstriction and sweating in the normal state. During general anesthesia, however, the body temperature regulation range becomes wider due to the increased sweating threshold and the decreased vasoconstriction threshold.

Positive end-expiratory pressure (PEEP) increases intrathoracic pressure and reduces the venous return. This causes carotid unloading, which leads to a secondary vasoconstriction and an increased thermoregulatory vasoconstriction threshold [2,3]. Nakajima et al. [4] reported that cardiac filling pressure or the level of baroreceptor loading influences the core temperature by modifying thermoregulatory peripheral vasoconstriction and Mizobe et al. [3] described the baroreceptor unloading by PEEP normally moderates perioperative hypothermia. Therefore, we investigated the effect of PEEP on the thermoregulatory reaction in TIVA (total intravenous anesthesia) using propofol-remifentanil.

\section{Materials and Methods}

Forty patients ranging in age from 20 to 65 years planning to undergo tympanoplasty as an elective operation were the subjects of this study. They were ASA (American Society of Anesthesiologists) class I or II. Those who had had thyroid disease, Raynaud syndrome, diabetes, or hypertension were excluded, in addition to those who were taking medicines for cardiovascular diseases or who were obese. Additionally, patients whose core temperature decreased to less than $34^{\circ} \mathrm{C}$ or administered drugs for hemodynamic stability were excluded. This study was approved by the institutional review board. The anesthetist visited the patients, and the caregivers on the day before the operation gave an explanation of the objective and methods of the study and received the patients' consent.

The subjects were randomly divided into two groups of 20 individuals. The group to which PEEP was not applied was named the ZEEP group, while the group to which a PEEP of $5 \mathrm{cmH}_{2} \mathrm{O}$ was applied was named the PEEP group. No preanesthetic administration was performed on the day of the operation. After arriving at the operating room, a patient monitoring instrument $\left(\mathrm{S} / 5^{\mathrm{TM}}\right.$ Anesthesia monitor, Datex-Ohmeda, Finland) was used to measure continuously the noninvasive blood pressure, pulse oxygen saturation, electrocardiograms, body temperature, and capnograms. The core temperature was measured with a tympanic thermometer (Thermoscan IRT 4020, Braun, Germany) before the induction, and after the induction, it was measured with an esophageal stethoscope installed at the region where the heartbeat was best heard. To measure the peripheral temperature, a thermometer for skin temperature measurement was attached to the patient monitoring instrument. This skin thermometer was installed on the middle part of the inside of the forearm where the blood pressure manometer was not bound and to the inside of the index finger tip using Tegaderm ${ }^{\mathrm{TM}}$ (3M healthcare, Germany). Fluid was not injected through the arm receiving temperature measurements. The temperature in the operating room was maintained at $22-24^{\circ} \mathrm{C}$ with an indoor thermometer (SH-104S, Saehan, Korea) near the patient's head.

For the induction, propofol-remifentanil was continuously injected at a target plasma concentration of $4 \mu \mathrm{g} / \mathrm{ml}$ and $2 \mathrm{ng} /$ $\mathrm{ml}$, respectively. Rocuronium $1.0 \mathrm{mg} / \mathrm{kg}$ was intravenously injected. After mask ventilation with $100 \%$ oxygen for five minutes, an endotracheal intubation was performed. The anesthesia was maintained by injecting propofol-remifentanil at target plasma concentrations of $3 \mu \mathrm{g} / \mathrm{ml}$ and $1.5 \mathrm{ng} / \mathrm{ml}$, respectively. The tidal volume was set to $10 \mathrm{ml} / \mathrm{kg}$, and the respiratory rate was controlled so that the end-expiratory carbon dioxide pressure could be maintained at $35-40 \mathrm{mmHg}$. The operating room was maintained at $22-24^{\circ} \mathrm{C}$. The entire body was covered with a sheet of surgical drape, except for the face. No other body heating was performed. The fluid used in the operation was lactated Ringer's solution that was heated to $37^{\circ} \mathrm{C}$. An appropriate degree of muscle relaxation was maintained by neuromuscular monitoring of the finger at which blood pressure was measured. The anesthetic depth was kept within the range of BIS 40-60 by attaching a BIS sensor to the forehead. Those for whom drug concentrations had to be adjusted by $\pm 20 \%$ or more to maintain vital signs or the anesthesia (BIS values) were excluded from the study. Then, the core temperature, the skin temperature at the forearm and the finger, the forearm-finger skin temperature difference, the mean blood pressure and the heart rate for three hours at 15-minute intervals were recorded. The point where the forearm-finger skin temperature difference reached $0^{\circ} \mathrm{C}$ was set as the thermoregulatory vasoconstriction threshold. When the forearm-finger skin temperature difference was less than $0^{\circ} \mathrm{C}$, peripheral vasodilation was assumed to be occurring [5-7].

All the results are presented as mean \pm standard deviation. A t-test was performed to evaluate statistical significance between 
the two groups for age, weight, height, mean blood pressure, heart rate, anesthetic duration, total fluid injection, initial core temperature, forearm-finger skin temperature difference, operating room temperature, vasoconstriction threshold, and the time it took to reach the vasoconstriction threshold. The empirical analysis of this study was tested with the significance level of $\mathrm{P}<0.05$. SPSSWIN 12.0 software was used for the statistical processing.

\section{Results}

No significant differences were found in the age, height, weight, anesthetic duration, and the total fluid injection between the two groups (Table 1). In addition, the mean blood pressure and heart rate did not show any significant differences between the two groups (Table 2). No significant difference existed between the two groups for the operating room temperature and the preanesthetic core temperatures (Table 3), but the core temperature drastically decreased after induction in both groups. Core temperature was significantly lower in the ZEEP group than in the PEEP group from 30 to 180 minutes after the induction (Fig. 1). The difference in the core temperature (the initial core temperature - the final core temperature) for the three hours was $2.0 \pm 0.3^{\circ} \mathrm{C}$ in the ZEEP group and $1.5 \pm 0.2^{\circ} \mathrm{C}$ in the PEEP group, indicating that the difference was significantly greater in the ZEEP group than in the PEEP group (Table 3). Peripheral thermoregulatory vasoconstriction was found in 13 subjects in the ZEEP group, and in 18 subjects in the PEEP group. The vasoconstriction threshold temperature was $35 \pm$

Table 1. Demographic and Anesthetic Characteristics

\begin{tabular}{lcc}
\hline & Group ZEEP $(\mathrm{n}=20)$ & Group PEEP $(\mathrm{n}=20)$ \\
\hline Age (yr) & $46.6 \pm 11.4$ & $48.8 \pm 10.0$ \\
Weight $(\mathrm{kg})$ & $62.9 \pm 10.8$ & $62.6 \pm 10.5$ \\
Height $(\mathrm{cm})$ & $163.8 \pm 11.1$ & $162.8 \pm 8.6$ \\
Anesthetic time (min) & $221.8 \pm 33.1$ & $240.8 \pm 36.4$ \\
Total fluid volume (ml) & $1836.0 \pm 352.2$ & $1912.5 \pm 268.0$
\end{tabular}

Values are mean \pm SD. There were no statistically significant differences between the groups. Group ZEEP: zero end expiratory pressure group, Group PEEP: $5 \mathrm{cmH}_{2} \mathrm{O}$ positive end-expiratory group. $0.4^{\circ} \mathrm{C}$ in the ZEEP group and $35.7 \pm 0.3^{\circ} \mathrm{C}$ in the PEEP group, indicating that it was significantly lower in the ZEEP group than in the PEEP group. The vasoconstriction duration was 116.2 \pm 26.3 seconds in the ZEEP group, and $78.0 \pm 15.7$ seconds in the PEEP group, showing that vasoconstriction duration was significantly shorter in the PEEP group (Table 3).

The forearm-finger skin temperature difference was

Table 3. Intraoperative Thermoregulatory Responses

\begin{tabular}{lcc}
\hline & $\begin{array}{c}\text { Group ZEEP } \\
(\mathrm{n}=20)\end{array}$ & $\begin{array}{c}\text { Group PEEP } \\
(\mathrm{n}=20)\end{array}$ \\
\hline Ambient temperature $\left({ }^{\circ} \mathrm{C}\right)$ & $23.5 \pm 0.5$ & $23.5 \pm 0.5$ \\
Preoperative core temperature $\left({ }^{\circ} \mathrm{C}\right)$ & $36.7 \pm 0.2$ & $36.6 \pm 0.3$ \\
Core temperature gradient & $2.0 \pm 0.3$ & $1.5 \pm 0.2^{*}$ \\
$(\mathrm{Ti}-\mathrm{Tf})\left({ }^{\circ} \mathrm{C}\right)$ & & \\
Vasoconstric number $(\mathrm{n}[\%])$ & $13(65 \%)$ & $18(90 \%)$ \\
Vasoconstric threshold $\left({ }^{\circ} \mathrm{C}\right)$ & $35.0 \pm 0.4$ & $35.7 \pm 0.3^{*}$ \\
Vasoconstric time $(\min )$ & $116.23 \pm 26.259$ & $78.00 \pm 15.681^{*}$ \\
\hline
\end{tabular}

Values are mean \pm SD or number (percent) of patients. Ti - Tf: initial core temperature - final core temperature. Group ZEEP: zero end expiratory pressure group, Group PEEP: $5 \mathrm{cmH}_{2} \mathrm{O}$ positive endexpiratory group. $* \mathrm{P}<0.05$ compared with Group ZEEP.

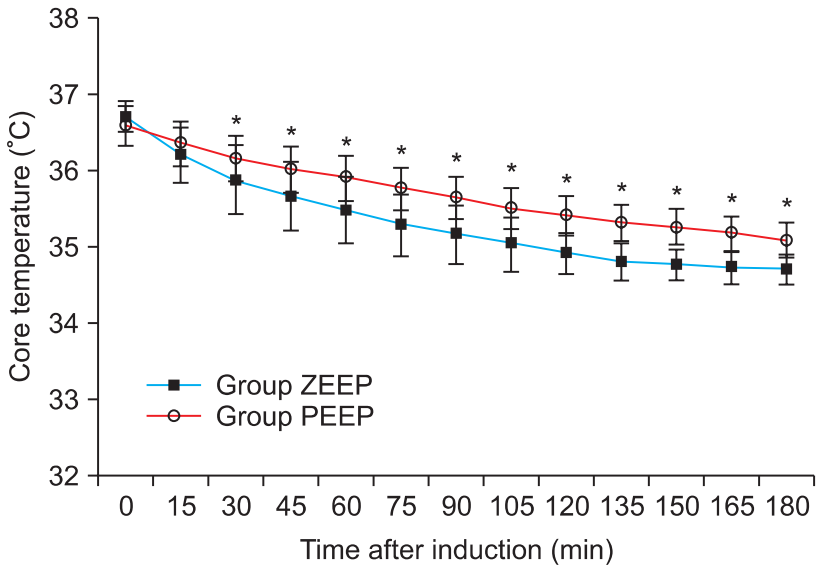

Fig. 1. Core temperature changes during anesthesia are shown. The core temperature of Group PEEP was significantly higher than that of Group ZEEP. It started from 30 minutes after induction of anesthesia until 180 minutes after induction. Group ZEEP: zero end-expiratory pressure, Group PEEP: $5 \mathrm{cmH}_{2} \mathrm{O}$ end-expiratory pressure. ${ }^{*} \mathrm{P}<0.05$ compared with Group ZEEP.

Table 2. Changes in the Mean Blood Pressure and Heart Rate

\begin{tabular}{|c|c|c|c|c|c|c|c|}
\hline & & $0 \mathrm{~min}$ & $\begin{array}{c}15 \mathrm{~min} \\
\text { after induction }\end{array}$ & $\begin{array}{l}30 \mathrm{~min} \\
\text { after induction }\end{array}$ & $\begin{array}{c}60 \mathrm{~min} \\
\text { after induction }\end{array}$ & $\begin{array}{l}120 \mathrm{~min} \\
\text { after induction }\end{array}$ & $\begin{array}{c}180 \mathrm{~min} \\
\text { after induction }\end{array}$ \\
\hline \multirow[t]{2}{*}{ MBP (mmHg) } & Group ZEEP & $86.7 \pm 10.9$ & $82.1 \pm 8.1$ & $80.0 \pm 6.7$ & $79.3 \pm 8.2$ & $78.7 \pm 7.2$ & $77.2 \pm 7.4$ \\
\hline & Group PEEP & $84.2 \pm 13.3$ & $78.0 \pm 10.1$ & $76.8 \pm 9.6$ & $76.2 \pm 9.3$ & $75.3 \pm 8.7$ & $74.5 \pm 7.4$ \\
\hline \multirow[t]{2}{*}{ HR (beats/min) } & Group ZEEP & $71.8 \pm 6.5$ & $66.5 \pm 8.1$ & $65.3 \pm 7.3$ & $64.9 \pm 6.8$ & $63.8 \pm 6.6$ & $63.6 \pm 6.3$ \\
\hline & Group PEEP & $73.4 \pm 9.9$ & $67.8 \pm 7.3$ & $66.7 \pm 6.7$ & $65.8 \pm 6.9$ & $63.9 \pm 6.8$ & $63.3 \pm 7.0$ \\
\hline
\end{tabular}

Values are mean \pm SD. There were no statistically significant differences between the groups. Group ZEEP: zero end expiratory pressure group, Group PEEP: $5 \mathrm{cmH}_{2} \mathrm{O}$ positive end-expiratory group, HR: heart rate, MBP: mean blood pressure. 


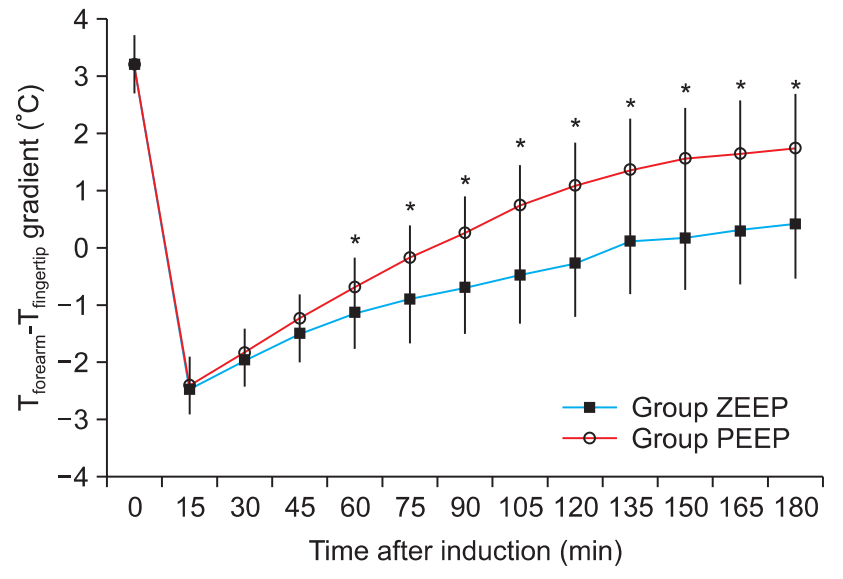

Fig. 2. The forearm minus fingertip temperature gradient $\left(\mathrm{T}_{\text {forearm }}-\right.$ $\mathrm{T}_{\text {finger }}$ ) is shown. The gradient of Group PEEP was significantly greater than that of Group ZEEP. It started from 60 minutes after induction of anesthesia until 180 minutes after induction. Group ZEEP: zero endexpiratory pressure, Group PEEP: $5 \mathrm{cmH}_{2} \mathrm{O}$ end-expiratory pressure. $* \mathrm{P}<0.05$ compared with Group ZEEP.

similar in the two groups before the anesthesia. It significantly decreased to $0^{\circ} \mathrm{C}$ or less after the induction and then gradually increased to $0^{\circ} \mathrm{C}$ or more over time. The skin temperature difference was significantly lower in the ZEEP group than in the PEEP group from 60 to 180 minutes after the induction, while the skin temperature difference of the PEEP group was closer to the preanesthetic reference value than was that of the ZEEP group (Fig. 2).

\section{Discussion}

In this study, we investigated the effect of PEEP on thermoregulatory responses during TIVA using propofol-remifentanil. The result showed that the core temperature was higher, the peripheral vasoconstriction was greater, the vasoconstriction threshold was higher, and the time of the vasoconstriction was earlier in the PEEP patient group than in the non-PEEP patient group.

A conscious person maintains their core temperature at approximately $37^{\circ} \mathrm{C}$ by active physical responses to body temperature change and by cold responses such as thermoregulatory vasoconstriction and shivering when the person is exposed to a cold environment [8]. The body temperature is not uniform throughout the body. The temperature of the cardiothoracic region, abdomen, and central nervous system (core temperature) is generally higher than that at the arms and legs by $2-4^{\circ} \mathrm{C}[2,9]$. The body strictly regulates the core temperature, while exposure to the environment and thermoregulatory vascular responses vary the temperature of the peripheral regions (e.g., arms and legs) [2]. However, the body temperature decreases during general anesthesia due to the lack of active body responses, decreased activity of the autonomic nervous system, and reduction of heat production for temperature regulation [2].

Hypothermia during a general anesthesia shows a typical pattern. The greatest cause of hypothermia during general anesthesia is the redistribution of heat from the core to the peripheral regions of the body by arteriovenous shunt extension and vasoconstriction threshold reduction [9]. Anesthetics used for general anesthesia severely repress normal autonomic thermoregulation, and thus slightly increase the heat response threshold (sweating threshold), greatly decrease the cold response threshold (the thermoregulatory vasoconstriction and shivering thresholds), and increase the inter-threshold range by more than 10 times [2,10-12]. Matsukawa et al. [1] observed the temperature change under TIVA using propofol and fentanyl and reported that body temperature was reduced by $1.6 \pm 0.3^{\circ} \mathrm{C}$ within one hour after the induction, and heat movement from the core to the peripheral regions accounted for $81 \%$ of the entire temperature reduction. These results show that during general anesthesia, the redistribution of heat from the core to the peripheral regions occurs through the $100 \mu \mathrm{m}$ thick arteriovenous shunt $[2,5]$.

However, little difference exists between the response to inhalation anesthetics and intravenous anesthetics. Propofol, alfentanil, and dexmedetomidine show a linear reduction of vasoconstriction and shivering thresholds. They slightly increase the sweating threshold. Isoflurane and desflurane nonlinearly decrease the vasoconstriction and shivering thresholds as they increase the sweating threshold [2,13-16]. The inhalation anesthetics decrease the vasoconstriction and shivering thresholds less than propofol at low concentrations, but they decrease them more than propofol at clinically high concentrations [2]. In contrast, Ikeda et al. [9] compared the core temperature of a group on which propofol $2.5 \mathrm{mg} / \mathrm{kg}$ was used for induction with that of another group, on which 5 vol\% sevoflurane was used. They reported that the core temperature was maintained at a lower level during the operation in the group on which propofol was used. However, comparing the effect of inhalation anesthetics with intravenous anesthetics in continuous anesthesia maintenance is difficult because propofol was used only for the induction and sevoflurane was used to maintain the anesthesia in both groups in the experiment. In addition, Iwata et al. [17] compared the core temperature in a neurosurgery in which propofol was used for the induction. A group in which propofol was used to induce the anesthesia and 1-2 vol\% sevoflurane was used to maintain the anesthesia was compared with another group in which propofol 3-5 $\mathrm{mg} / \mathrm{kg} / \mathrm{min}$ was used. They reported no significant difference between the two groups. Kwak et al. [18] reported no significant difference in the core temperature between a group 
of burn patients in which both the induction and maintenance of the anesthesia were performed by continuous intravenous injection of propofol-remifentanil and another group in which the induction was performed with propofol and the anesthesia maintenance was performed with sevoflurane. Im et al. [19] also reported no significant difference in the core temperature between groups in which propofol-remifentanil anesthesia and sevoflurane-remifentanil anesthesia were used. Summarizing these results, intravenous anesthetics and inhalation anesthetics do not show a significant difference in common clinical dosage, even though the vasoconstriction threshold is dependent upon the dose.

In this study, anesthesia was induced using propofol-remifentanil and maintained in patients undergoing tympanoplasty. The subjects were divided into two groups by the application of PEEP to observe variations in body temperature. The differences between the two groups in the vasoconstriction and core temperatures may be because of reduced stimulation of the baroreceptors and reduced right atrial transmural pressure. Using the PEEP application increased the vasoconstriction threshold and thus repressed that temperature decrease. Mizobe et al. [3] observed the variation of the core temperature using the PEEP application during inhalation anesthesia, reporting that the core temperature was higher in the PEEP-applied patients than among patients under anesthesia. Nakajima et al. [4] reported that the core temperature was higher in subjects to which PEEP was applied because the application of PEEP increased the vasoconstriction threshold and subsequently repressed the temperature drop. They stated that the increased stimulation on the baroreceptors using the leg-up position could accelerate the temperature drop. This is consistent with our result. However, the Mizobe et al. [3] findings differed from ours in terms of the degree of core temperature decrease and the time when the forearm-finger skin temperature difference increased, which may be because other variables such as the operation room temperature, the body temperature measurement method, and the amount of injected fluid were involved. Nakajima et al. [20] also investigated the core temperature variation by injecting a cold fluid into conscious, unanesthetized subjects in the sitting and the supine position. They found that the temperature drop was greater in the subjects in the sitting position. They stated that the result was because increased peripheral sympathetic nervous system activity and an increased level of norepinephrine in the sitting position directly or indirectly reduced the adrenaline input to the brain stem and repressed the hypophysial responses. This then repressed the central regulatory cold responses and heat generation, and also seems to show that heat generation participates more in thermoregulation than thermoregulatory vasoconstriction in unanesthetized patients.
Since most anesthetics cause a decrease in body temperature, anesthetized patients can easily fall into hypothermia. This causes platelet dysfunction and coagulation disorder, which can repress immunologic function and lead to an infection due to blood flow reduction. Additionally, catecholamine is secreted as the sympathetic system is stimulated, thus increasing the risk of postoperative heart complications. Moreover, hypothermia is related to delayed wound healing, delayed recovery from anesthesia, increased hospitalization time, and increased oxygen consumption caused by shivering $[2,18,21,22]$. Therefore, various methods should be used to prevent intraoperative hypothermia during TIVA with propofolremifentanil.

In conclusion, the application of PEEP in TIVA was found to reduce intraoperative hypothermia by repressing the core temperature drop and increasing the vasoconstriction threshold.

\section{Acknowledgements}

This study was supported by research funds from Chosun University, 2010.

\section{References}

1. Matsukawa T, Sessler DI, Sessler AM, Schroeder M, Ozaki M, Kurz A, et al. Heat flow and distribution during induction of general anesthesia. Anesthesiology 1995; 82: 662-73.

2. Sessler DI. Temperature monitoring and perioperative thermoregulation. Anesthesiology 2008; 109: 318-38.

3. Mizobe T, Nakajima Y, Sunaguchi M, Ueno H, Sessler DI. Clonidine produces a dose-dependent impairment of baroreflex-mediated thermoregulatory responses to positive end-expiratory pressure in anaesthetized humans. Br J Anaesth 2005; 94: 536-41.

4. Nakajima Y, Mizobe T, Takamata A, Tanaka Y. Baroreflex modulation of peripheral vasoconstriction during progressive hypothermia in anesthetized humans. Am J Physiol Regul Integr Comp Physiol 2000; 279: R1430-6.

5. Rubinstein EH, Sessler DI. Skin-surface temperature gradients correlate with fingertip blood flow in humans. Anesthesiology 1990; 73: 541-5.

6. Belani K, Sessler DI, Sessler AM, Schroeder M, McGuire J, Merrifield $\mathrm{B}$, et al. Leg heat content continues to decrease during the core temperature plateau in humans. Anesthesiology 1993; 78: 856-63.

7. Kurz A, Sessler DI, Birnbauer F, Illievich UM, Spiss CK. Thermoregulatory vasoconstriction impairs active core cooling. Anesthesiology 1995; 82: 870-6.

8. Sessler DI. Temperature regulation and monitoring. In: Miller's anesthesia. 7th ed. Edited by Miller RD, Ericksson LI, Fleisher LA, Wiener-Kronish JP, Young WL: Philadelphia, Churchill-Livingstone. 2009, pp 1533-4.

9. Ikeda T, Sessler DI, Kikura M, Kazama T, Ikeda K, Sato S. Less core hypothermia when anesthesia is induced with inhaled sevoflurane 
than with intravenous propofol. Anesth Analg 1999; 88: 921-4

10. Frank SM, Beattie C, Christopherson R, Norris EJ, Rock P, Parker $\mathrm{S}$, et al. Epidural versus general anesthesia, ambient operating room temperature, and patient age as predictors of inadvertent hypothermia. Anesthesiology 1992; 77: 252-7.

11. Sessler DI. Temperature regulation and monitoring. In: Miller's anesthesia. 7th ed. Edited by Miller RD, Ericksson LI, Fleisher LA, Wiener-Kronish JP, Young WL: Philadelphia, Churchill-Livingstone. 2009, pp 1542-3.

12. Washington D, Sessler DI, Moayeri A, Merrifield B, Prager M, McGuire $\mathrm{J}$, et al. Thermoregulatory responces to hyperthermia during isoflurane anesthesia in humans. J Appl Physiol 1993; 74: 82-7.

13. Matsukawa T, Kurz A, Sessler DI, Bjorksten AR, Merrifield B, Cheng C. Propofol linearly reduces the vasoconstriction and shivering thresholds. Anesthesiology 1995; 82: 1169-80.

14. Kurz A, Go JC, Sessler DI, Kaer K, Larson MD, Bjorksten AR. Alfentanil slightly increases the sweating threshold and markedly reduces the vasoconstriction and shivering thresholds. Anesthesiology 1995; 83: 293-9.

15. Ikeda T, Kurz A, Sessler DI, Go J, Kurz M, Belani K, et al. The effect of opioids on thermoregulatory responses in humans and the special antishivering action of meperidine. Ann N Acad Sci 1997; 813: 792-8.

16. Xiong J, Kurz A, Sessler DI, Plattner O, Christensen R, Dechert M, et al. Isoflurane produces marked and nonlinear decreases in the vasoconstriction and shivering threshold. Anesthesiology 1996; 85: 240-5.

17. Iwata T, Inoue S, Kawaguchi M, Takahashi M, Sakamoto T, Kitaguchi $\mathrm{K}$, et al. Comparison of the effects of sevoflurane and propofol on cooling and rewarming during deliberate mild hypothermia for neurosurgery. Br J Anaesth 2003; 90: 32-8.

18. Kwak IS, Kim SH, Woo CH, Kim KM. Effect of inhaled sevoflurane and intravenous propofol with remifentanil on the core body temperature in burn patients. Anesth Pain Med 2008; 3: 118-22.

19. Im UJ, Lee DJ, Kim MC, Lee JS, Lee SJ. Difference in core temperature in response to propofol-remifentanil anesthesia and sevoflurane-remifentanil anesthesia. Korean J Anesthesiol 2009; 57: 704-8.

20. Nakajima Y, Takamata A, Ito T, Sessler DI, Kitamura Y, Shimosato $\mathrm{G}$, et al. Upright posture reduces thermogenesis and augments core hypothermia. Anesth Analg 2002; 94: 1646-51.

21. Lopez M, sessler DI, Walter K, Emerick T, Ozaki M. Rate and gender dependence of the sweating, vasoconstriction, and shivering thresholds in humans. Anesthesiology 1994; 80: 780-8.

22. Stoen R, Sessler DI. The thermoregulatory threshold is inversely proportional to isoflurane concentration. Anesthesiology 1990; 72: 822-7. 